\title{
Treatment of Conjunctival Malignant Melanoma with Topical Interferon Alpha-2a
}

\author{
Naser Salihu', Belinda Pustina1, Brigita Drnovšek-Olup ${ }^{2}$ \\ ${ }^{1}$ Department of Ophthalmology, University Clinical Center of Kosova, \\ Prishtina, Kosova \\ ${ }^{2}$ Eye Clinic, University Medical Center Ljubljana, Ljubljana, Slovenia \\ Email: belindapustina@gmail.com
}

Received 19 May 2015; accepted 24 July 2015; published 28 July 2015

Copyright (C) 2015 by authors and Scientific Research Publishing Inc.

This work is licensed under the Creative Commons Attribution International License (CC BY). http://creativecommons.org/licenses/by/4.0/

(c) (i) Open Access

\begin{abstract}
Conjunctival malignant melanoma (CMM) is a potentially lethal neoplasm with a high rate of recurrence. The modality of treatment includes a wide surgical excision, cryotherapy, topical mitomycin $C$ and Interferon alpha $2 b$ (INF $\alpha 2 b$ ). The aim of the study is to present the treatment of a case with CMM using topical Interferon alpha 2a. We present a 38-year-old female with diffuse bulbar dark pigmentation of the conjunctiva that arises from previously primary acquired melanosis (PAM). Biopsy resulted positive for CMM and further investigations were negative for any metastasis. Treatment with topical interferon alpha 2 a was started immediately and after three months melanoma disappeared. One year after follow-up there was no sign of recurrence in regional lymph nodes or distant metastasis.
\end{abstract}

\section{Keywords}

\section{Conjunctival Malignant Melanoma, Interferon Alpha 2a}

\section{Introduction}

CMM is a rare but potentially lethal neoplasm with a high rate of recurrence and accounts for about $2 \%$ of all ocular malignancies [1]. It usually arises from PAM in $75 \%$ of cases and $20 \%$ from conjunctival pre-existing nevus or de novo. The modality of treatment includes a wide "no touch" surgical excision with adjuvant double freeze cryotherapy and tumor free margins of $4 \mathrm{~mm}$, cryotherapy or topical chemotherapy with mitomycin $\mathrm{C}$ and INF $\alpha 2$ b. The overall mortality is about $12 \%$ at 5 years and $25 \%$ at 10 years [2] [3].

We report a case of CMM treated with topical interferon alpha 2a. 


\section{Case Presentation}

A 38-year-old lady presented with diffuse bulbar dark pigmentation of the conjunctiva in her right eye. There was no history of any surgical treatment in the eye or otherwise.

Slit-lamp examination showed the dark colored lesion in her right eye that involved complete bulbar conjunctiva in superior and inferior nasal quadrants, perilimbal parts of cornea and caruncula (Figure 1).

Other examinations included visual acuity 1.0 (Snellen), intraocular pressure $13.0 \mathrm{mmHg}$ AP, and a normal fundus. US-B scan resulted with no intraocular extension of the mass. The orbit and brain MRI, chest X-ray and an ultrasound of the abdomen and pelvis were normal. All blood examination results were also within normal limits.

No metastases were detected in regional lymph nodes or in distant organs.

Diagnosis was verified by histopathological examination. Immunohistochemistry was positive for HMB 45, Ki 67, CD 68 and AEI/3.

The left eye was normal.

After discussions with the patient, with her consent, we started the treatment with topical INF $\alpha-2 a, 1 \mathrm{MIU} / \mathrm{ml}$, qid. To our knowledge, this subtype of interferon alpha was never used before in the treatment of CMM. The treatment comprised of three sessions over a month. The changes started disappearing immediately after the first session and completely withdrew after the third (Figure 2). We didn't notice any local or systemic side effects during the treatment. The patient will undergo continuous monthly check-ups.

There was no evidence of local recurrence or distant metastasis one year after treatment.

\section{Discussion}

CMM are relatively rare tumors, but their importance lies in their potential to cause death. Early detection is

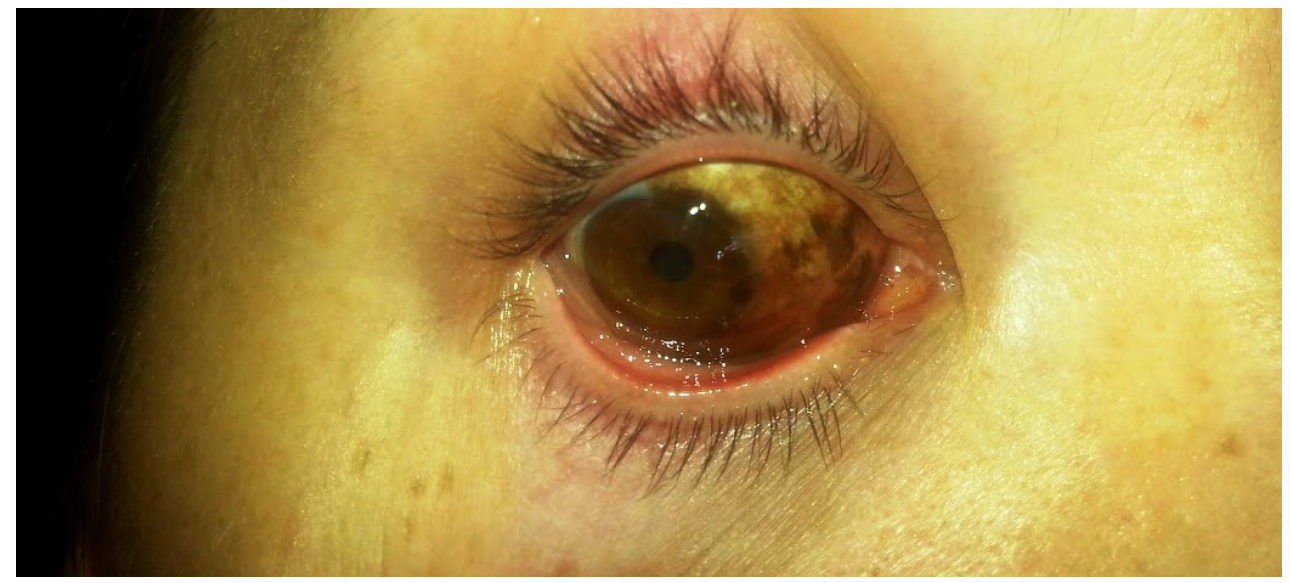

Figure 1. Right eye: pigmented nodules of nasal bulbar conjunctiva, cornea and caruncula.

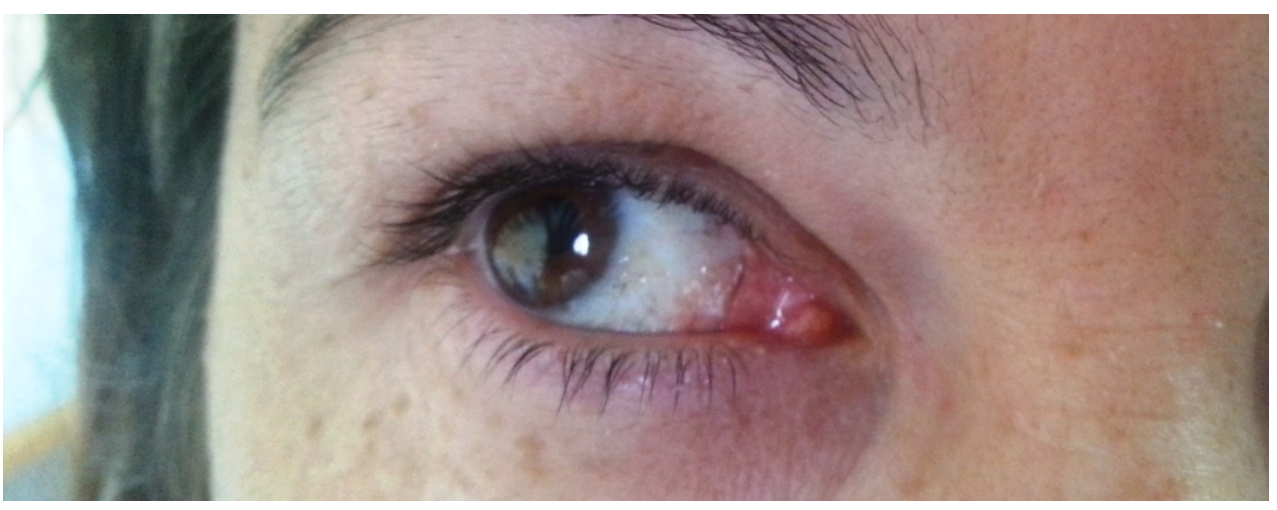

Figure 2. Right eye: after treatment with topical interferon alpha 2a. 
very critical in initiating treatment and in preventing a lethal course.

Management of CMM is by surgical excision. Topical treatment has been taken in consideration lately especially in cases with wide conjunctival involvement. One of the topical drugs used in the treatment of CMM is INF [4].

INF is a natural multifunctional protein. Depending on the molecular structure they are classified as alpha, beta or gamma INF.

Antiproliferative activity of human IFN- $\alpha$ is deemed to consist of direct and indirect activities. Direct activity occurs through cancer cell growth inhibition by cell cycle arrest, apoptosis or differentiation. Indirect activity occurs through activation of immune cells such as $\mathrm{T}$ cells and natural killer cells, inhibition of vascularization (antiangiogenesis), and induction of cytokines [5].

The treatment of CMM with IFN alpha-2b is known. We have no evidence of someone reporting having used IFN apha-2a. We used INF alpha 2a because it was the only one available in our institution. The topical application of INF $\alpha$-2a proved to be highly efficacious in our case. No local or systemic side effects were encountered during the treatment. There is no evidence of local recurrence or distant metastasis one year after the treatment. A year is certainly a small period of time to conclude on the efficacy of this treatment in one case. However, we are continuously monitoring the patient regarding long-term effects, the results of which we intend to publish later.

\section{Conclusion}

Topical INF $\alpha$-2a, $1 \mathrm{MIU} / \mathrm{ml}$ qid for 3 months has been shown to be beneficial in treating CMM. No evidence of recurrence was noticed one year after follow-up. Further studies are required to assess the long-term safety in treating CMM.

\section{References}

[1] Misra, S., Misra, N., Gogri, P., Reddy, V. and Bhandari, A. (2013) A Case of Conjunctival Malignant Melanoma with Local Recurence. Australasian Medical Journal, 6, 344-347. http://dx.doi.org/10.4066/AMJ.2013.1728

[2] Shields, C.L., Kels, J.G. and Shields, J.A. (2015) Melanoma of the Eye: Revealing Hidden Secrets, One at a Time. Clinics in Dermatology, 33, 183-196. http://dx.doi.org/10.1016/j.clindermatol.2014.10.010

[3] Kanski, J.J. and Bowling, B. (2011) Clinical Ophthalmology: A Systematic Approach. 7th Edition, Elsevier Saunders, Edinburgh, 482-483.

[4] Finger, P.T., Sedeek, R.W. and Chin K.J. (2008) Topical Interferon Alfa in the Treatment of Conjunctival Melanoma and Primary Acquired Melanosis Complex. American Journal of Ophthalmology, 145, 124-129. http://dx.doi.org/10.1016/j.ajo.2007.08.027

[5] Ningrum, R.A. (2014) Human Interferon Alpha-2b: A Therapeutic Protein for Cancer Treatment. Scientifica, 2014, Article ID: 970315, 8 p. 